Territorios 33 / Bogotá, 2015, pp. 103-122

ISSN: 0123-8418

ISSNe: 2215-7484

Procesos de ocupación del territorio, historia urbana y patrimonio II

\title{
Paisagem e patrimônio cultural em imagens: um estudo sobre São Miguel das Missões, Brasil
}

\section{Landscape and Cultural Heritage in Images: A Study of São Miguel das Missões, Brazil}

Paisaje y patrimonio cultural en imágenes: un estudio sobre San Miguel Mission, Brasil

Darlan de Mamann Marchi*

Maria Leticia Mazzucchi Ferreira ${ }^{\star *}$

Recebido: 8 de septiembre de 2014

Aprovado: 27 de marzo de 2015

Doi: dx.doi.org/10.12804/territ33.2015.05

Para citar este artigo:

Marchi, de M. D., \& Ferreira, M. M. L. (2015). Paisagem e patrimônio cultural em imagens: um estudo sobre São Miguel das Missões, Brasil. Territorios, 33, 103-122. Doi: dx.doi.org/10.12804/territ33.2015.05

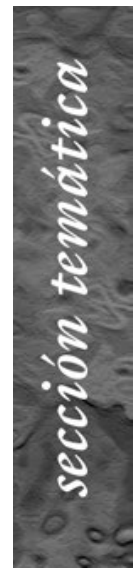

* Licenciado em História pela Universidade Regional Integrada do Alto Uruguai e das Missões (URI-Santo Ângelo). Possui mestrado em Memória Sociale Patrimônio Cultural pela Universidade Federal de Pelotas. Doutorando do Programa de Pós-Graduação em Memória Social e Patrimônio Cultural da Universidade Federal de Pelotas, Bolsista Capes. E -mail: darlanmarchi@ gmail.com

* Professora Associada da Universidade Federal de Pelotas. Atua como docente e pesquisadora na área de Patrimônio, principalmente nos seguintes temas: patrimônio industrial, patrimônio imaterial, politicas públicas de patrimônio, memória, museus. É docente no Programa de Pós-Gra- $\Rightarrow$ 
Palavras-chave

Patrimônio, paisagem, São Miguel das Missões.

Palabras clave

Patrimonio, paisaje, São Miguel das Missões.

Keywords

Heritage, landscape, São Miguel das Missões.

territarias 33 104

\section{RESUMO}

São Miguel das Missões, no estado brasileiro do Rio Grande do Sul, é uma pequena cidade que possui um patrimônio cultural mundial reconhecido pela Unesco. Os remanescentes arquitetônicos do antigo povoado jesuítico-guarani de São Miguel Arcanjo compõem a paisagem da cidade, que se desenvolveu no entorno do sítio tombado. A cidade moderna da atualidade convive com o patrimônio cultural protegido pelo Estado, o que possibilita analisá-la sobre dois aspectos: a ação do Estado na constituição das identidades dos moradores locais e a constituição da paisagem da cidade a partir e com o sítio histórico tombado. Através de fotografias de diferentes períodos é possível perceber que o visível e o subjetivo trabalharam e trabalham juntos na composição do lugar, nesse quase um século de ações preservacionistas do patrimônio cultural missioneiro na localidade.

\section{RESUMEN}

São Miguel das Missões, en el estado brasileño de Rio Grande do Sul, es una pequeña ciudad que cuenta con un patrimonio cultural mundial reconocido por la Unesco. Los restos arquitectónicos de la antigua aldea jesuitico-guaraní de San Miguel Arcángel conforman el paisaje de la ciudad, que se desarrolló en las inmediaciones del sitio patrimonializado. La ciudad moderna de hoy convive con el patrimonio cultural protegido por el Estado, lo que permite analizarla en dos aspectos: la acción del Estado en la constitución de las identidades de los habitantes locales y la constitución del paisaje de la ciudad desde y con el sitio histórico patrimonializado. Por medio de fotografías de diferentes épocas es posible percibir que lo visible y lo subjetivo trabajaron y trabajan juntos en la composición del lugar, en ese casi un siglo de acciones de preservación del patrimonio cultural misionero en la localidad.

\section{ABSTRACT}

São Miguel das Missões, in the brazilian state of Rio Grande do Sul, is a small town that has a world cultural heritage recognized by Unesco. The architectural remnants of the former Jesuit-Guarani village of São Miguel Arcanjo is the landscape of the city, which developed around of the heritage archaeological site. The modern city of today coexists with cultural heritage protected by the State, which enables analyzing it on two aspects: the action of the State in the constitution of identities of the people and the constitution of the city landscape from heritage historic site. After observing photographs of different periods is possible to notice that the visible and the subjective worked and work together in the construction of the place, for about a century of preservationists actions of missionary cultural heritage in the locality. 


\section{Introdução}

Resultado de um projeto colonizador iniciado no século XVI, associado às intenções evangelizadoras dos religiosos jesuítas da Companhia de Jesus, as reduções implantadas no território que hoje pertence ao Brasil, Argentina e Paraguai foram marcantes na constituição das fronteiras e no processo de colonização desse território. ${ }^{1}$ Religiosos e nativos de diferentes etnias, com predominância do povo guarani, foram atores da construção de alguns aldeamentos, a maioria dos quais sobrevindos em ruínas na atualidade.

Igrejas, escolas, casas, claustro, capelas, pomares, oficinas, cotiguaçu, ${ }^{2}$ estâncias para criação de animais e plantações, são alguns dos elementos que faziam parte do complexo do aldeamento missioneiro. Essas estruturas construtivas implantadas foram modificando a paisagem das densas matas do entorno dos rios Uruguai, Paraná e seus afluentes. O planejamento urbano dos povoados seguia projetos pré- estabelecidos pelos religiosos, entretanto, como afirma Baptista (2009), a disposição e organização dos povoados seguiam as especificidades de organizações culturais próprias de cada grupo indígena. Para esse autor, questões de ordem cultural dos Guarani influenciaram na disposição desses espaços e nos modos de vida, o que se fazia estratégico para efetivar o projeto das reduções.

Em território brasileiro, sete povoados se consolidaram após cessar as ações dos bandeirantes ${ }^{3}$ sobre as Reduções, período que a historiografia passou a denominar de segundo ciclo missioneiro. Se incluídos os territórios hoje pertencentes à Argentina e Paraguai, o número total chegou a 30 povoados. "En 1632 había 24 pueblos; en 1633: 31 ; en 1647:20; en 1695: 25; 1702:29 y en 1707 existían treinta pueblos y ese número va a continuar desde 1719 hasta 1768, año de la expulsión [dos jesuítas]" (Palacios \& Zoffoli, 1991, p. 111).

São Miguel Arcanjo, fundada em 1687, foi descrita pelo Padre Antônio Sepp como a maior de todas as reduções. A ele coube o trabalho de dividir a população de mais de 6 mil pessoas em 1697, para a fundação de outro povoado que viria a ser o de São João Baptista (Sepp, 1980). Pe. Sepp ao discorrer sobre a necessidade da divisão da população de São Miguel destaca que a primeira igreja do povoado não mais comportava esse número de habitantes.

A igreja que hoje predomina como bem material em evidência no sitio histórico patrimonializado, foi construída entre os anos de 1729 e 1749, conforme Stello (2005). O pesquisador discute, a partir de diferentes autores, alguns pontos sobre o projeto de Gian Battista Primoli - arquiteto jesuíta, responsável por diferentes obras nos domínios jesuítas na região do Pratapara o templo de São Miguel. A inspiração estaria na Igreja de Gesú (1568) em Roma (Stello, 2005).

Nas figuras 1 e 2 é possível observar comparativamente as duas obras na contemporaneidade, uma vez que o que se deseja, através desse texto, é refletir sobre a presença icônica que a figura da igreja de duação em Memória Social e Patrimônio Cultural da Universidade Federal de Pelotas. Coordenadora de Relações Internacionais da Universidade Federal de Pelotas. E-mail: leticiamazzucchi@gmail.com.

${ }^{1} O$ método colonizador reducional com as populações autóctones nessa região envolveu também outras congregações religiosas, como os Franciscanos. Resultado da proposta das Leis de Indias e com a eficácia dessa experiência em território do vice-reino do Peru, o método das missões obteve reconhecimento. A ação dos jesuitas inicia com a fundação de San Ignácio Gasú no ano de 1609. Até o ano de 1643 foram ao todo 43 reduções, que não se mantiveram, entre outras dificuldades, devido aos ataques dos bandeirantes paulistas (Meliá \& Nagel, 1995, p. 103).

territarias 33

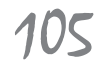


${ }^{2}$ Koty, casa/quarto, guaçu, grande. Espaço destinado ao acolbimento de necessitados, idosos, órfãos, viúvas. Segundo Baptista (2009), o espaço que primeiramente era destinado a essas populações em estado de risco, como velhos éorfãos, passou a ter um papel de segregação de gênero, uma vez que a mulher dentro da estrutura cristã europeia era vista como uma ameaça aos desígnios divinos. Sendo assim, no povoado esse lugar passou a exercer uma forma de controle sobre as mulheres viúvas, órfãs ou abandonadaspelosseusmaridos, na tentativa de evitar a poligamia.

${ }^{3}$ As bandeiras eram compostas por homens que partiam de São Paulo rumo ao interior do continente como objetivo de capturar indios para mão-de-obra escrava, que servia aos engenhos de açucar e para outros trabalhos. Os bandeirantesfaziam da captura e venda de escravos indigenas uma atividade comercial lucrativa no século XVI e XVII. As missões jesuitico-guaranis no sul do continente sofreram inumerosataques para a captura dos guaranis que se encontravam aldeados. Asconstantese violentas investidas dos bandeirantes nas reduções da região do Tape - que abrange o atual $\Rightarrow$

territarias 33
Figura 1. Igreja de Gesú - Roma/Itália

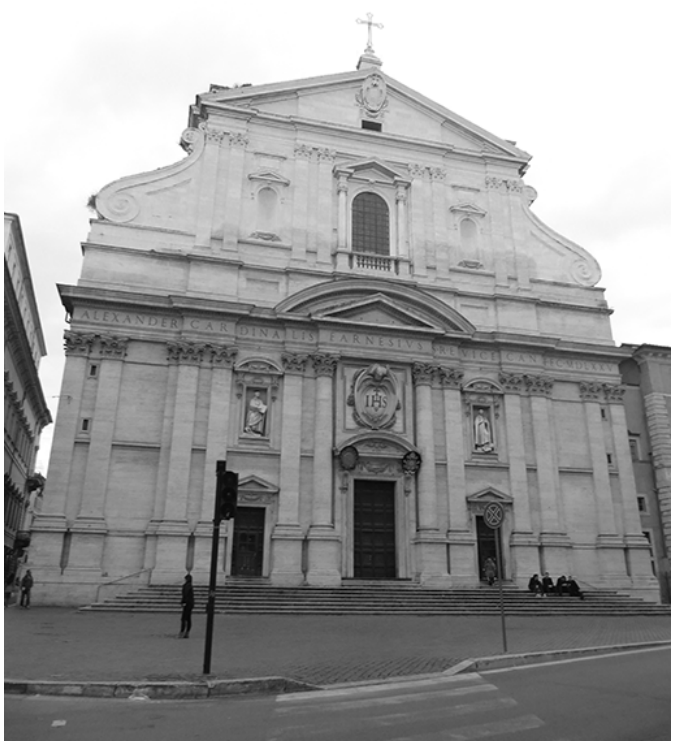

Fonte: Foto Darlan De M. Marchi. Março de 2014.
São Miguel Arcanjo vai ganhando na paisagem do lugar, sendo o elemento visual de maior relevância na composição do espaço patrimonializado. Com base nos traços da igreja romana, o arquiteto milanês Gian Battista Primoli projetou o templo e inseriu detalhes que poderiam aumentar ainda mais a dramaticidade do barroco, tal como aborda (Custódio, 1994), quando observa que a fachada da igreja apresenta uma inclinação propositalmente feita para aumentar a visão do templo em perspectiva.

Com as disputas fronteiriças e as guerras de domínio do território, passando pelo fim do período reducional e o relativo abandono do povoado, e mais tarde pelo repovoamento e a revalorização do lugar, somam-se mais de dois séculos e meio nos quais vão se configurando diferentes senti-

\section{Figura 2. Igreja do Sítio Histórico de São Miguel das Missões - Rio Grande do Sul/Brasil}

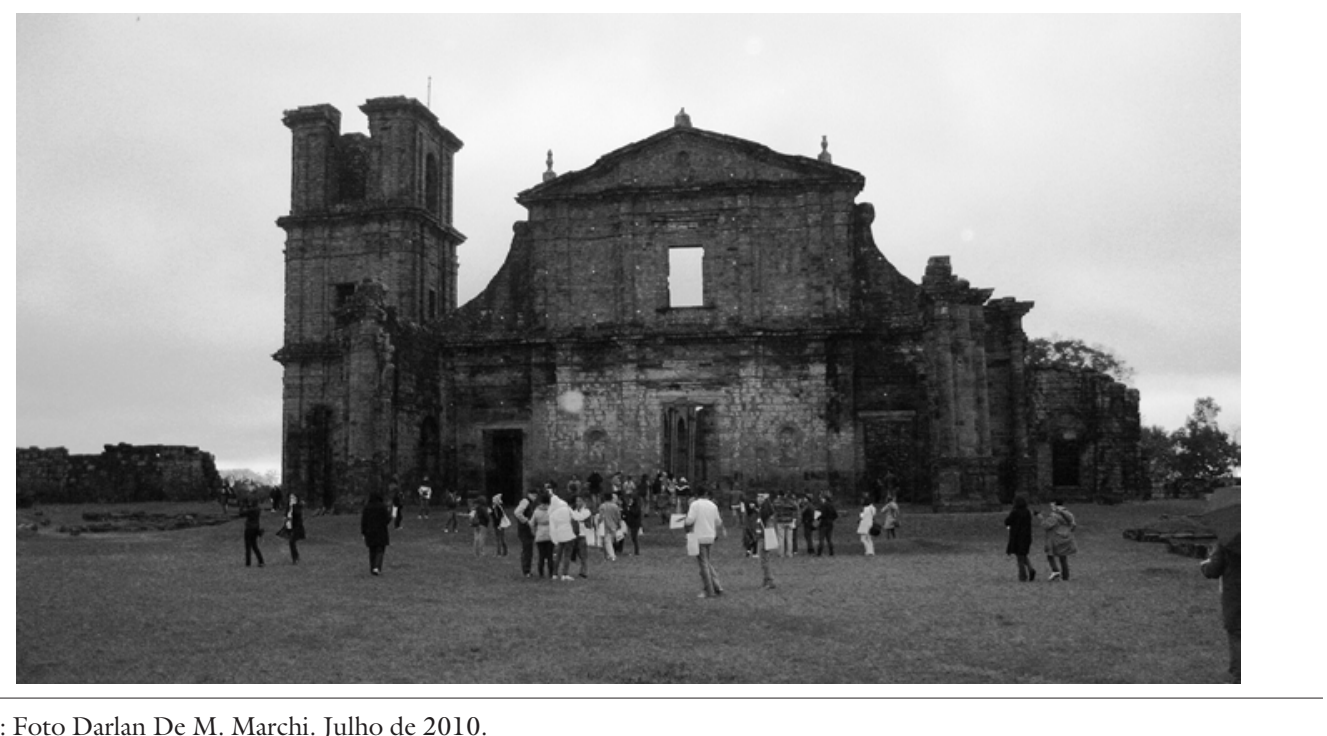

Fonte: Foto Darlan De M. Marchi. Julho de 2010.

Darlan de Mamann Marchi, Maria Leticia Mazzucchi Ferreira 
dos de envolvimento da população local e do Estado frente a esse espaço. O uso como lugar de culto dentro do contexto reducional até a consagração como parte de um espaço cultural tombado como patrimônio mundial refletem mudanças na paisagem e no próprio significado da antiga catedral. Esse elemento de pedra, popularmente chamado "ruína", foi definidor na constituição física da cidade contemporânea e também obteve outros significados através das intencionalidades refletidas nas ações protetivas e também dos diferentes olhares lançados sobre o que hoje se configura como monumento.

\section{A constituição de um patrimônio cultural das Missões}

Durante o século XIX, São Miguel das Missões, assim como os demais povoados do lado oriental do rio Uruguai, passou aos domínios da coroa portuguesa após um conflito bélico, quando os exércitos de Portugal e Espanha fizeram cumprir o Tratado de Madrid de 1750, também chamado "tratado de permuta", no qual a região foi trocada pela Colônia de Sacramento junto à bacia do Prata, hoje território uruguaio. Conforme Meliá e Nagel (1995), a ação desse tratado pode ser analisada sobre três períodos: o primeiro (1750-1753) refere-se ao acordo das coroas na Europa e o impacto causado entre os índios e jesuítas quando da notícia da transmigração da população; o segundo (1753-1760) trata da insurreição indígena e as expedições dos exércitos de Espanha e Portugal que leva- ram à "guerra guaranítica" com a derrota dos guaranis e a tomada dos povoados; e a terceira, (1756-1761) com a propaganda anti-jesuítica e a desmoralização dos guaranis por parte dos poderes instituídos, bem como processos investigativos e a anulação do tratado que já havia causado a desestruturação dos povoados.

Os anos que se seguiram após todo esse quadro desencadeado pelo tratado, foram marcados pelo arrefecimento populacional do território, embora os povoados seguissem habitados por poucos indígenas e outros atores sociais -imigrantes, viajantes, forasteiros, posseiros - reconfigurando assim o território missioneiro. Após inúmeros furtos e saques no que restara dos povoados, em 1827 São Miguel das Missões contava com apenas 83 habitantes (Palacios \& Zoffoli, 1991).

Ao longo do século XIX inúmeros são os relatos de viajantes que passaram pela região e deixaram seus depoimentos sobre a situação de abandono no qual se encontravam as antigas reduções. Jean Baptista e Maria Cristina Santos (2009) trazem alguns desses registros de viajantes, como o de Nicolau Dreus que registrou:

Ali a civilização retrogradou: o silêncio do deserto estende-se pouco a pouco sobre essas vilas outrora florescentes, e o trabalho lento, mas incansável da destruição, que já não se vê paralisado pela mão reparadora do homem, vai de dia em dia desmoronando esses templos, elegantes e as moradas numerosas e regulares que os circundam; ele restringe e aniquila gradualmente as culturas dessa ter-
Rio Grande do Sul -, obrigou os jesuitas a solicitarem autorização do rei espanbol para que armassem os indigenas com a finalidade de defender os povoados. Devidamente armados, no ano de 1641, os guaranis derrotaram os bandeirantes na Batalha de Mbororé e passaram a viver, a partir dessa data, um relativo periodo de tranquilidade na região (Meliá é Nagel, 1995, p. 113-114).

territarias 33

107 
${ }^{4}$ Com a anulação do Tratado de Madrid, uma nova ordem de organização político-administrativa foi instaurada na região dos povoados que compunham as missões. As tentativas de inserir novas ordens religiosas para o cuidado dos povoados, bem como a nomeação de administradores leigos espanhóis, levou a disputas de poder entre curas e representantes da coroa. As mudanças constantes no sistema de ocupação dos povoados com o aval para a ocupação de terras vagas por criollos levou a desorganização do sistema anterior e a criação de um cenário que promoveu a deserção dos indigenas, a mestiçagem da população, além de casos de corrupção, a criação de novas relações para a ocupação e consequentemente a crise e o arruinamento das estruturas fisicas dos povoados de outrora (Santos, 2009, p. 23-98).

\section{territarias 33} 108 ra fecunda onde dimanava a abundância e a fortuna do país Santos, 2009, p. 202 apud Dreus [1817-1839] 1839, p. 101).

Em relação ao povoado de São Miguel, o viajante botânico Auguste de Saint-Hilaire narra a situação do povoado em 19 de março de 1820. Entre as descrições feitas sobre o lugar, Saint-Hilaire destaca, já naquele momento a necessidade de reparo e manutenção dos bens construídos, e refere-se à intenção de uma restauração por parte do poder público ainda naquele período:

São Miguel, a mais bem administrada de todas as aldeias que visitei até agora. Além das casas que formam a praça, vêem-se várias ruas. $\mathrm{O}$ curralão está em bom estado. A casa do cabildo necessita de reparos, mas existe ainda. A igreja, construída pelos jesuítas, inteiramente de pedra, possui uma torre que servia de campanário, mas há vários anos uma tormenta caiu sobre o telhado, destruindo-o completamente. João de Deus, um dos primeiros governadores portugueses desta província, pretendia fazer reparos neste edifício; juntou materiais, gastou muito dinheiro, mas com a mudança de governo, o sucessor não aprovou o seu projeto. As restaurações da igreja foram interrompidas, as despesas feitas tornaram-se inúteis.

\section{$[\ldots]$}

São Miguel é a primeira aldeia onde vejo realizar algumas reparações. Se, no início, tivessem atacado essas obras, quando necessário, as aldeias não estariam à beira de total destruição, mas numa região em que não se conserva o patrimônio público, não se pode esperar que os administradores cujo principal interesse é o lucro se dessem ao trabalho de mandar fazer reparos nas edificações que não lhes pertencem, e de que se importam bem pouco (Saint-Hilaire [1779-1853], 2002, pp. 373-374).

O viajante francês Alfred Demersay realizou o primeiro registro imagético do povoado de São Miguel do qual se tem notícias, no ano de 1846 (figura 3). A imagem de Demersay retrata o avanço desse período de abandono que se abateu sobre as contruções do período jesuítico-guarani e, assim como os relatos dos viajantes, a litografia passou a ter grande importância para as atividades de valorização dos remanescentes materiais que seriam empreendidas ao largo do século Xx (Brasil \& Minc-Iphan, 1994).

O francês que viajava pela região da antiga República do Paraguai reproduziu a imagem da igreja que começava a ser tomada pela vegetação. Ao lado esquerdo do desenho ainda era possível observar os prédios que compunham o claustro e outros imóveis, em estado de abandono. No século XVIII, após a expulsão dos jesuítas, as missões permaneceram ainda sob a administração de Buenos Aires, desencadeando-se nesse período todo um processo de paulatina desestruturação dos povoados. ${ }^{4}$ No período em que foi feito o desenho, o espaço já pertencia à Portugal que tratando com descaso a região contribuiu para o abandono dos bens construídos como se pôde perceber nos trechos dos relatos de Nicolau Dreus e de Auguste de Saint- 


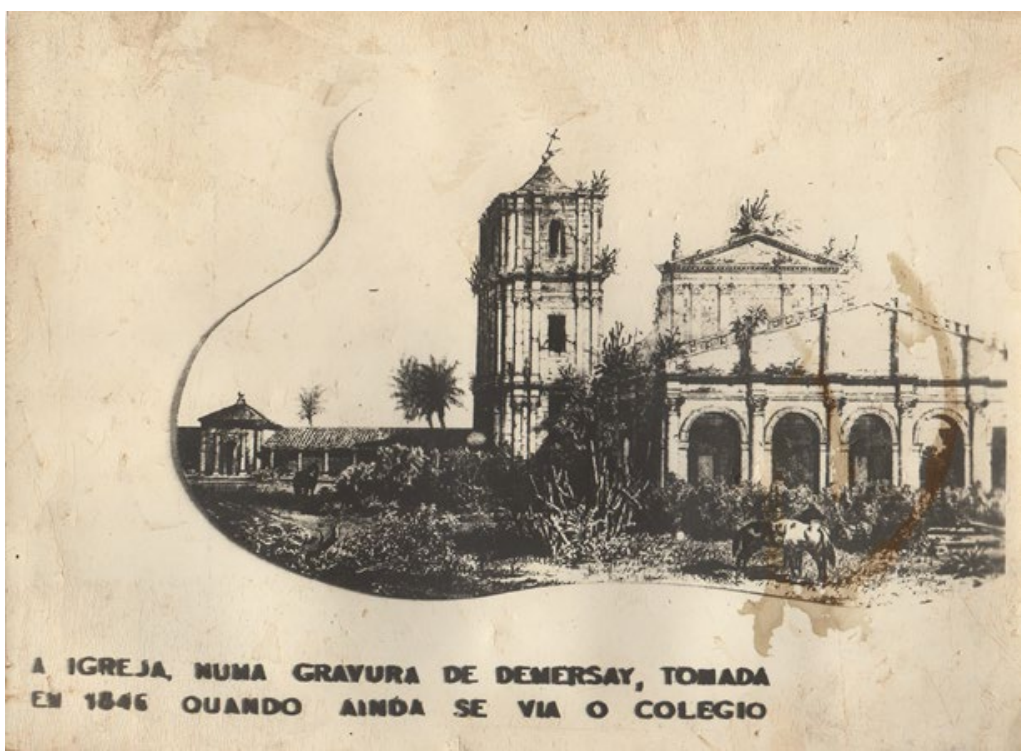

Fonte: Acervo da fototeca do Arquivo Histórico Municipal Augusto César Pereira dos Santos (AHMACPS), Santo Ângelo.

-Hillaire, trazidos anteriorrmente. Os saques de obras sacras, pedras e as ações de aventureiros e caçadores de tesouros também aceleraram o processo de degradação das antigas reduções.

Em finais do século XIX e princípios do século XX, a ação dos governos para a colonização dos territórios estendeu a posse das terras a famílias influentes e colonos imigrantes, conforme a Lei de Terras. ${ }^{5}$ Essa nova configuração do território deu início à urbanização de São Miguel, distrito da recém-criada Vila de Santo Ângelo, outro dos antigos aldeamentos jesuíticos-guarani que foi repovoado e obteve a sua emancipação político-administrativa no ano de 1873. Os remanescentes arquitetônicos do antigo povoado jesuítico-guarani são men- cionados nos documentos de demarcação dos novos lotes e chácaras que vão sendo definidos pela Intendência Municipal. ${ }^{6}$

Em documento dirigido ao Conselho Municipal de Santo Ângelo, em 3 de agosto de 1881, os novos moradores da Vila de São Miguel solicitam providências em relação a conflitos nas demarcações das terras para a povoação urbana do povoado:

Ilm ${ }^{\circ}$ Srs. Presidente e vereadores da Comarca Municipal de Santo Ângelo.

Dizem os infrascriptos, residentes no Pôvo velho de S. Miguel, terceiro Districto do Termo de Santo Angelo, que estando os antigos heréos confinantes do mesmo Pôvo mandando valar terrenos, que cabe três, quatro moradores e mais, nas próprias
5 Lei do Império $n^{o}$ 601/1850, que "Dispõe sobre as terras devolutas no Império, e acerca das que são possuidas por titulo de sesmaria sem preenchimento das condições legais, bem como por simples titulo de posse mansa e pacifica; $e$ determina que, medidas e demarcadas as primeiras, sejam elas cedidas a titulo oneroso, assim para empresas particulares, como para o estabelecimento de colonias de nacionaes e de extrangeiros, autorizado o Governo a promover a colonisação extrangeira na forma que se declara”. Disponivel em < http://www. planalto.gov.br/ccivil_03/ Leis/L0601-1850.htm>.

${ }^{6}$ A partir do decreto $N^{o}$ 2672 de 20 de outubro de 1875 que "Autoriza o Governo a alienar as terras das aldêas extinctas que estiverem aforadas", a municipalidade de Santo Ângelo passa a vender lotes urbanos no distrito de São Miguel.

territarias 33 109 
ruas gesuiticas, obstando desta forma que se povôe o lugar, [...] e dizendo ou fazendo compreender que o Pôvo resume-se apenas na antiga praça e algumas braças mais de terreno; vem por isso, os Supptes. Cheios de confiança nessa honrosa e illustrada corporação pedir justiça, esperando allivio para semelhante mal $[\ldots]$

Os infrascriptos Ilmos. Srs. precisão ver dissipadas estas duvidas para saberem se de facto S. Miguel é um Pôvo em o qual fôra creada ultimamente uma Capella curada, ou se pelo contrario é efhémero, ficando toda a população do mesmo Pôvo redusida a aggregados destes heréos confincentes, o que se assim fôr, ficará em breve despovoado (AHMACPS, Intendência, Caixa 20).

A despeito dos conflitos prementes aos primeiros anos da recolonização, vê-se que a referência à praça central, onde se localizava os remanescentes arquitetônicos da redução, era apontada como centro da urbe pelos habitantes que permaneciam na localidade. A demarcação oficial dos terrenos por parte da prefeitura para o povoamento da localidade vai ocorrer somente na década de 1920. No Jornal A Semana, de 24 de fevereiro de 1921, encontra-se uma nota intitulada "Os terrenos de S. João e S. Miguel", que relata a visita do intendente de Santo Ângelo Coronel Braulio de Oliveira e do agrimensor Heitor Pinheiro Machado às localidades dos antigos povoados para os primeiros contatos a fim de proceder as medições dos terrenos e a promoção de um traçado organizado para as vilas, algo

\section{territarias 33} 110 que, segundo o periódico, era esperado há muito tempo pelos habitantes dos povoados. (A Semana, 1921).

Em caderno de campo da demarcação dos terrenos urbanos da Vila de São Miguel datado 1927, constante do acervo do Arquivo Histórico Municipal Augusto César Pereira dos Santos (AHmacPs) de Santo Ângelo, está descrito os procedimentos do trabalho de medição que é oficializado em documento de 03 de novembro de 1929 pelo intendente Dr. Ulysses Rodrigues. Entre as delimitações do distrito com seus terrenos e chácaras, encontra-se oficializado um espaço denominado "ruínas", que media um total de $86.352 \mathrm{~m}^{2}$.

Pouco tempo antes, nesse mesmo período da segunda metade da década de 1920, mais precisamente entre 1925 e 1927, através do governo do Estado do Rio Grande do Sul foram realizadas as primeiras intervenções de manutenção nas ruínas do templo, com investimentos designados pela Diretoria de Terras da Secretaria do Estado e Obras Públicas (Stello, 2005). Ainda em 1922 o relatório desta instituição traz, segundo Ana Meira (2008) a delimitação de "Lugares Históricos", conferindo essa distinção a lugares representativos da história gaúcha. A autora destaca o uso do termo "lugar", uma concepção que somente chegaria ao âmbito dos estudos de patrimônio quase cinquenta anos mais tarde.

Na região missioneira, assim como em outras localidades gaúchas, a estrutura verticalizada da política republicana mantivera seu poderio de base através da estrutura expressa por Loiva Otero Félix (1996) das forças dos coronéis/chefes militares 
e seus agregados/soldados. ${ }^{7}$ Esse período foi marcado pelo clima acirrado entre republicanos e federalistas, que em 1923 desencadearam violentos confrontos. $\mathrm{O}$ fim dos combates veio através de acordo no qual o governo de Borges de Medeiros saía da guerra civil mantendo o seu poder, porém o Partido Republicano Rio-Grandense (PRR) perdia forças no quadro político que até então o assegurava no poder desde os primeiros anos da republica brasileira. Nesse cenário, a ação de valorização de lugares como as ruínas de São Miguel como bens de valor histórico pelo governo do estado possivelmente visava à afirmação de referenciais históricos que, num contexto político de crise, afirmassem o modelo coronelista e patrimonialista que até então dominava a cultura política gaúcha.

Na década seguinte, com a Revolução de 1930 e a chegada de Getúlio Vargas à presidência da república, é criado o Serviço do Patrimônio Histórico e Artístico Nacional (SPHAN) em 1937 e que, com o apoio de intelectuais modernistas, promoveu escolhas de bens materiais a ser preservados em todo o Brasil com a finalidade de definir os referenciais da identidade nacional. Nesse mesmo ano, o arquiteto Lucio Costa foi enviado para o Rio Grande do Sul, onde, por intermédio do literato gaúcho Augusto Meyer, recorreu os remanescentes dos Sete Povos das Missões e propôs através de relatório providências para a preservação, o que resultaria no tombamento de alguns desses remanescentes como patrimônio nacional em 1938 (Meira, 2008). Sobre as ações posteriores ao tombamento, o texto oficial que apresenta São Miguel das Missões no site do IPHAN afirma que,

Dois anos depois, foi criado o Museu das Missões, destinado ao recolhimento e à guarda da estatuária da Igreja de São Miguel. Além disso, entre 1938 e 1940, o arquiteto Lucas Mayerhofer dirigiu as obras de estabilização da igreja e a construção do prédio do Museu, cujo projeto original foi elaborado por Lucio Costa. ${ }^{8}$

Lúcio Costa ${ }^{9}$ projetou o museu (figura 4) inspirado no que teria sido uma das habitações indígenas dos povoados missioneiros (Custódio \& Stello, 2007). Criado ofialmente pelo decreto lei nacional $\mathrm{n}^{\circ}$ 2077 de 08/03/1940 e inaugurado pouco tempo depois, o museu passou a compor a paisagem do lugar. Através de suas linhas sóbrias e inserido no espaço do sítio como um prédio moderno mas com referências coloniais, o prédio guarda em suas salas a exposição das obras sacras missioneiras recolhidas na região pelo Sr. Hugo Machado, primeiro zelador do museu. A ruína da igreja, como testemunha material do período jesuítico-guarani, e o museu, como materialização das obras contemporâneas de afirmação patrimonial do lugar, mostram ao visitante o entrecruzamento de dois passados, um mais remoto, do tempo histórico que confere sentido ao lugar, e outro mais recente, da representação destes bens como o tempo do patrimônio.

Assim, a intervenção do Estado nesses primeiros anos de reconhecimento do patrimônio cultural das Missões, tanto do
7 O jornal A Semana, publicado em Santo Angelo nesse periodo, possuía claro objetivo politico para a propaganda do Partido Republicano em inúmeras noticias e artigos. (Acervo do Arquivo Histórico de Santo Ângelo - edições entre 1919 e 1923).

${ }^{8}$ Missões Jesuitas Guaranis no Brasil, ruinas de São Miguel das Missões. Disponivel em: <http://portal.iphan. gov.br/montarDetalheConteudo.do;jsessionid $=F 4$ 794396D02B497213F61 $11 E 706$ A15E2? $i d=17248$ essigla=Institucionaler reto $r n o=$ detalheInstitucional $>$.

9 Importante arquiteto modernista brasileiro que galgou fama internacional pelo projeto do Plano Piloto de Brasília, capital federal do Brasil construida na segunda metade da década de 1950.

\section{territarias 33}

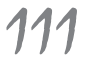


Figura 4. Museu das Missões em 1974. Vista da lateral. Levantamento Fotográfico

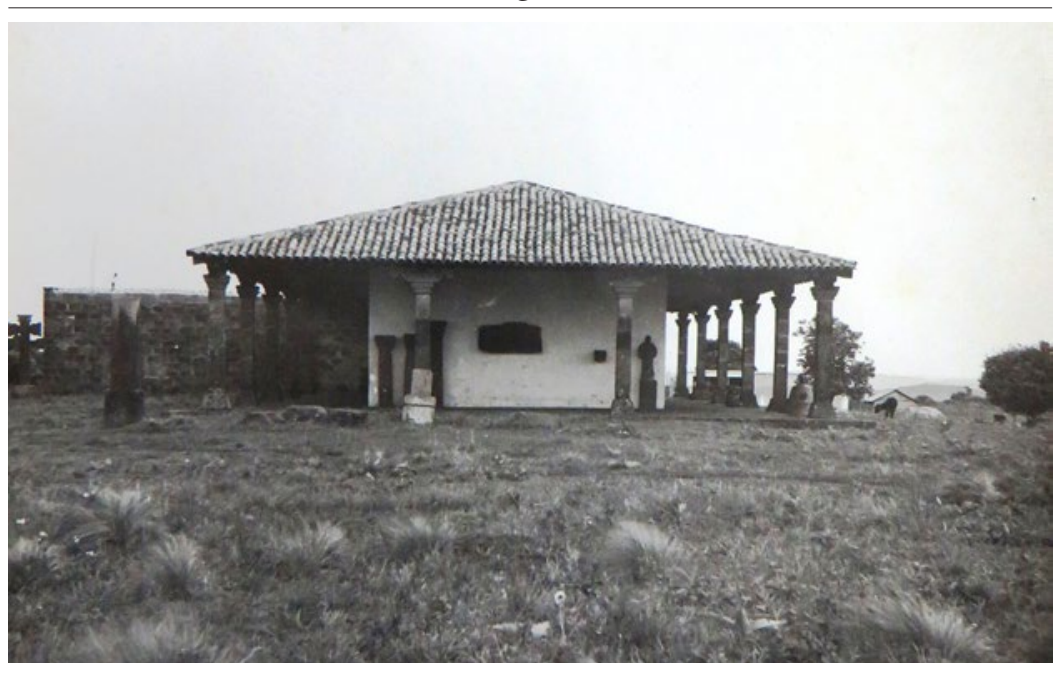

Fonte: Ruínas de São Miguel RS, 07 /74 Município de Santo Ângelo. Arquivo do IPHAN São Paulo.

${ }^{10}$ Assim como outros numeros da mesma revista publicados pelo então Serviço do Patrimônio, vinculado ao Ministério da Educação e Cultura, sob a coordenação de Rodrigo de Melo Franco Andrade - disponiveis no endereço eletrônico do IPHAN na internet-o periódico discorre sobre vários bens culturais nacionais. Os artigos assinados por diversos artistas e intelectuais versam sobre bens culturais de diferentes estados do país e que estavam sendo oficialmente reconhecidos, legitimando assim a ação do Estado, as escolhas e as ações de preservação dos bens edificados.

territarias 33

governo do Rio Grande do Sul como do governo federal, fazem parte de um quadro político de transformações. O enfraquecimento das oligarquias rurais e as políticas estadonovistas vão delinear os discursos sobre o patrimônio cultural.

Para compreender melhor o processo que levou à valorização desse patrimônio, resulta importante recorrer a Llorenç Prats (1998) e sua definição sobre o conceito de ativação patrimonial como sendo o processo que envolve a tríade: natureza, história e genealidade, o que definiria o bem cultural escolhido. O destaque dado a um bem material combina a narrativa romantizada do bem e a força da transmissão simbólica capaz de converter-se em emoções intensas. A região missioneira, com destaque para as Ruínas de São Miguel, através da ação con- tínua do Estado, da criação de um museu, de regras e legislações para manutenção, criou um discurso sobre o passado, cuja eficiência da transmissão esteve sempre associada aos dispositivos patrimoniais.

Em 1940, Alberto Lamego na Revista do SPHAN $^{10}$ iniciava um texto sobre os Sete Povos das Missões com a seguinte frase: "No extremo noroeste do Estado do Rio grande do Sul, à margem esquerda do Rio Uruguai, está situada a cidade de São Francisco de Borja, onde viu a luz do sol o Sr. Getulio Vargas e que foi um dos Sete Povos das Missões”. Mais adiante, no mesmo texto novamente exalta a figura do presidente e demonstra o tom nacionalista apregoado pelas políticas patrimoniais do período:

Agora que o grande estadista que dirige a Nação faz reviver das cinzas do passado os dias gloriosos dos "Sete Povos das Missões", considerando monumentos históricos as suas igrejas em ruínas determinando, por decreto, a sua restauração e a organização de um museu, na de São Miguel, para guarda das relíquias esparsas a elas pertencentes, que o tempo ainda não destruiu, é de toda oportunidade darmos notícia das festas realizadas no Povo de São Francisco de Borja há quase dois séculos (Lamego, 1940, p. 56).

O artigo de Lamego, além da transcrição de documentos que registravam os festejos religiosos no povoado de São Borja, dava destaque ao lugar de nascimento de Getulio Vargas, visto pelo autor como um missioneiro que havia chegado ao poder. $\mathrm{O}$ tom nacionalista da valoração da figura do 
mandatário da nação, ligando-o ao passado glorioso das missões, denotava também um discurso de legitimação ideológica de um governo autoritário. Conforme Colvero (2013),

De 1930 a 1934, Vargas governou o país no chamado governo provisório e, com a nova Constituição, foi eleito Presidente por um colégio eleitoral. No entanto, este dá um golpe de Estado em 1937, inaugurando o Estado Novo. Essa nova etapa representou importante modificação para o Brasil em seu "sistema institucional", pois houve a quebra no processo democratizador e a instauração de um governo enérgico, principalmente no que concerne ao controle absoluto das várias instâncias públicas por parte do Estado (p. 126).

Dentro desse contexto político, a elevação das ruínas a monumento nacional se afirmava na abordagem das mesmas como representativas de um modelo de experiência promissora de cooperação empreendida entre europeus e indígenas. Tal experiência vinha também ao encontro do discurso em voga no período: o da integração das raças na formação do país. Todavia, o papel do indígena como protagonista nas missões só seria reconhecido décadas mais tarde.

\section{As ruínas e a constituição da paisagem}

As ruínas da Igreja de São Miguel, reabilitadas assim pela ação do Estado, provocam o que Françoise Choay (2006) chamou de "emoção estética", quando a beleza arquitetônica unida à ação do tempo que deteriora a obra, provoca emoção e "integra o monumento histórico ao novo culto da arte, chamado a substituir aquele de um Deus".

Entretanto, mesmo com a intencionalidade do Estado na preservação e com toda a atenção dedicada por setores sociais que lhe delegaram o valor do reconhecimento oficial através de suas retóricas de afirmação nacionalista, há que se afirmar o valor intrínseco desse bem cultural. Seu valor histórico como testemunha de um período colonial que reflete uma experiência de associação de referências culturais de grupos sociais distintos, ${ }^{11}$ é por si só um marco robusto da memória do lugar. Lugar este marcado também, pela qualidade arquitetônica de seu templo religioso.

De acordo com Alois Riegl, (2005) o monumento pode ser valorado pela sua antiguidade, ou seja, a ação do tempo que provoca a deterioração, por seu valor histórico que detém a depreciação a partir do momento em que se torna referencial material de um acontecimento do passado. Esse entendimento é validado por Choay (2006) quando aborda que, na perspectiva da gênese do conceito moderno de patrimônio, o século XIX foi por excelência o tempo de desvelamento das ruínas, sobretudo as greco-romanas, para um turismo histórico de maiores proporções. A passagem do mérito de antiguidade, para a importância histórica e consequentemente para o valor rememorativo intencional - terceiro estágio desse processo, segundo
${ }^{11}$ Buscando a superação de um ideário historiográfico eurocentrista que propalava uma ideia de aculturação dos gruposindigenasnas Missões, e exortava o papel dos jesuitas como detentores da cultura que dava sentido à experiência missioneira,é que os historiadores contemporâneos têm trabalhado. Jean Baptista (2008) em artigo sobre os problemas de classificação das obras do Museu das Missões, fala da invisibilidade do indigena na exposição das obras sacras do museu, uma vez que a estética das obras produzidas por mãos nativasé resultante do diálogo das divindades cristãs com as crenças dos indigenas, num processo de transformação desses significados mesclados na materialidade das pinturas e dos entalhes em madeira.

territarias 33

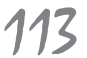


12 São Miguel das Missões tornou-se cidade independente administrativamente da cidade de Santo Angelo através d Lei estadual ${ }^{\circ}$ 8584 de 29 de abril de 1988. Na atualidade o municipio possui uma população de 7.421 hab. Numa extensão total de 1,229, $883 \mathrm{~km}^{2} \mathrm{com}$ uma economia baseada na área de agropecuária e serviços. (Fonte: Instituto Brasileiro de Geografia e Estatística - IBGE. Disponivel em: <http://www.cidades. ibge.gov.br/painel/painel. php? lang = co codmun $=431$ 915 ersearch $=$ rio-grande-do-sul\%7Csao-miguel-das-missoes\%7Cinfograficos:-dados-gerais-do-municipio>.

\section{territarias 33} 114
Riegl, e que trata da ação da restauraçãopode ser visualizado a partir das imagens da Igreja de São Miguel.

A evolução do processo de ativação do patrimônio missioneiro pode ser analisada através de imagens fotográficas de São Miguel. A paisagem do sítio histórico preservado vai sendo redimensionada com as ações patrimoniais, através das quais as ruínas foram sendo confirmadas como centrais no lugar e a cidade moderna, ${ }^{12}$ que hoje existe no entorno, foi sendo equilibrada em sua expansão nas periferias do patrimônio.

Conforme Letícia Castilhos Coelho (2012), "como um palimpsesto, um enigma a ser interpretado, a paisagem se apresenta em imagens como possibilidade de compreensão do tempo presente" (p. 207). Assim como os relatos de viagem, as fotografias também atuam sobre a construção da uma realidade de um determinado espaço, como afirma Paulo Cesar da C. Gomes (2012). A construção do que o autor chama de "olhar geográfico" passa pela observação da imagem a partir do ponto de vista de quem fotografa, da composição e da exposição da fotografia.

As fotografias antigas das ruínas da igreja da antiga redução demonstram o olhar valorativo que começava a ser lançado sobre os bens materiais do antigo povoado missioneiro de São Miguel Arcanjo. Algumas fotografias de antigos moradores que se encontram no acervo do Arquivo Histórico de Santo Ângelo, trazem homens, mulheres e crianças posando para a câmera em frente à ruína da antiga igreja por volta das décadas de 1920 e 1930. Nessas décadas estava em processo a urbanização da vila, ainda distrito de Santo Ângelo, que trazia para o território novos atores sociais que lançavam um olhar de admiração sobre o lugar. Esse processo denotava a apreciação das ruínas agora como monumento.

Figura 5. Imagem do interior da igreja antes das obras promovidas pelo governo do RS.

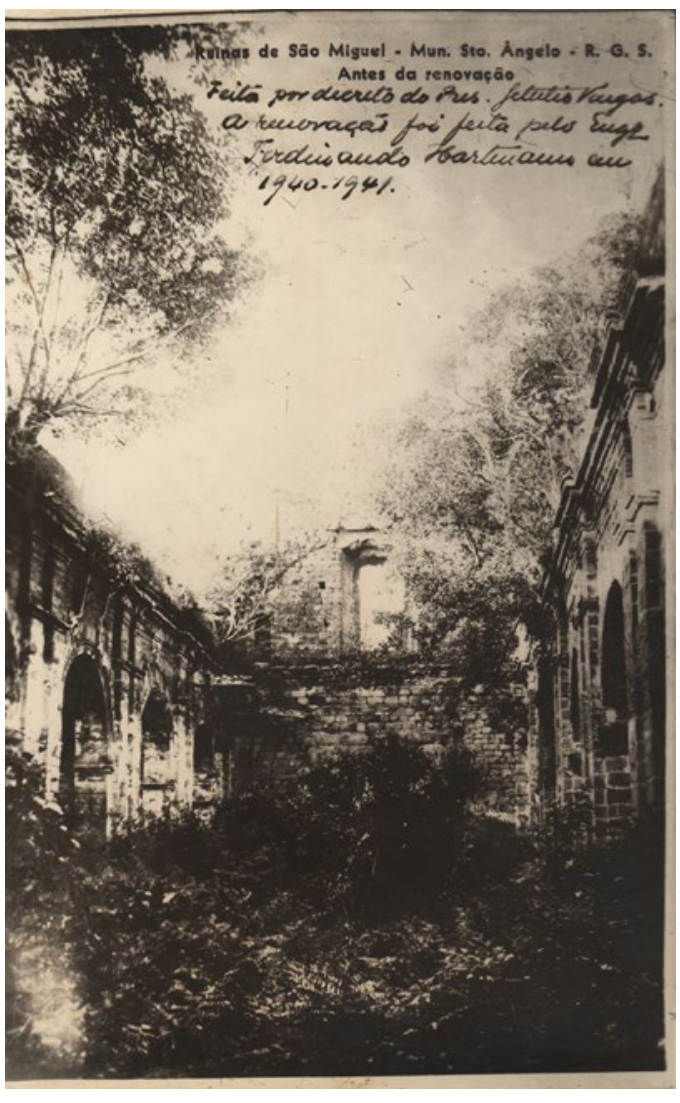

Fonte: Imagem da fototeca do acervo do AHMACPS. Santo Ângelo/RS. Década de 1920. Autoria desconhecida. 
A visualização da paisagem na fotografia da figura 5 se dá na perspectiva de mostrar o interior das ruínas da antiga igreja de São Miguel tomadas pela vegetação. $\mathrm{O}$ fotógrafo posicionado ao fundo do templo, na área que seria ocupada pelo altar, procura registrar as paredes interiores e contrastar a grandeza da obra em relação às frondosas árvores que cresceram nas naves da igreja e que impediam a visualização da porta principal. Na fotografia está o seguinte registro escrito: "Ruinas de São Miguel - Mun. Sto. Ângelo - R.G.S. Antes da renovação" logo mais abaixo o seguinte manuscrito: "Feita por decreto do pres. Getúlio Vargas. A renovação foi feita pelo $\mathrm{Eng}^{\circ}$ Ferdinando Hartmann em 1940-1941". A inscrição ignora as interveções realizadas na década de 1920, e também erra no nome do responsável pela restauração do templo em 1940 que foi o Arq. Lucas Mayerhofer, que da mesma forma foi responsável pelas obras da construção do prédio do Museu das Missões. Apesar disso, o que interessa aqui é o significado que a fotografia foi obtendo no contexto da construção da paisagem. As fotografias das ruínas tomadas pela vegetação passaram a ser um registro importante das ações de restauro do templo. A partir delas foi possível mostrar o antes e o depois, e como a atuação do poder público deixava sua marca no lugar. Os usos posteriores destas imagens pelas instituições públicas, simultaneamente à construção do quadro imagético pela disposição dos elementos na paisagem, as colocam como um documento da atuação do Estado como protagonista nesse processo de recuperação de
Figura 6. Imagem externa da igreja possivelmente no período das obras promovidas pelo governo do RS

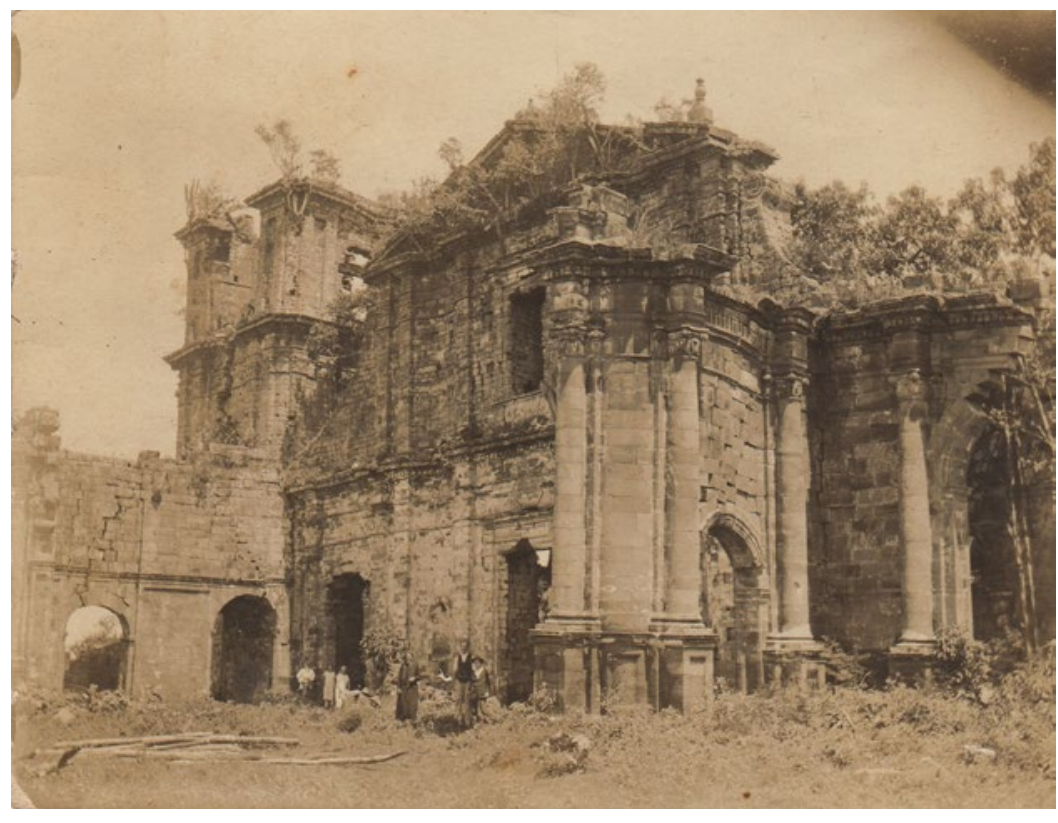

Fonte: Fototeca do acervo do AHMACPS. Santo Ângelo/RS. Década de 1920. Fotógrafo: Kurt Michael.

um espaço que serviria para a rememoração do colonial missioneiro.

Na imagem da figura 6, também se vê no alto as árvores que cresceram dentro e nas pedras, daquele que um dia foi um espaço de culto. Todavia, a parte externa da igreja já estava livre da mata cerrada que antes encobria o cenário, alguns troncos de árvores encontram-se sobre a grama no lado esquerdo da imagem. A fotografia, feita possivelmente por um fotógrafo amador, previlegiou o cenário com a fachada da igreja, e as pessoas presentes na imagem, em frente à porta de entrada, se apequenam diante da predominância das ruínas. Pode- territarias 33

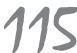


-se perceber a torre ainda danificada assim como as pedras sobre os arcos entre as colunas laterais, o que denota que o trabalho de estabilização das paredes ainda não havia iniciado. Contudo, a fotografia demonstra já o princípio valorativo monumental da ruína, o assombro causado pelas paredes de pedra que despontavam agora na paisagem sem o mato que antes as encobriam. Sandra Pesavento (2007) afirma que existe nas ruínas uma ambiguidade representativa, pois remetem simultaneamente a algo que se decompõe pela ação do tempo, e também que pode ser recuperado pela contemplação, pela significação dada através daquele que olha e, que, a partir de suas referências imagéticas próprias ou herdadas, confere a estas, no conjunto do espaço, o status de "paisagem da memória".

Nos postais das figuras 7 e 8 , já se pode ver a igreja estabilizada, predominantemente estabelecida no centro da paisagem nas fotografias de Bruno Schmidt, renomado fotógrafo da região nas décadas 1940 e 1950. O sítio oficialmente reconhecido e protegido como patrimônio nacional desponta no centro do povoado moderno de São Miguel das Missões. Na figura 7 o fotógrafo enquadra a ruína ao fundo, emoldurada no alto, à direta, por uma das grandes árvores dispersas pelo sítio. No postal da figura 8 vê-se a perspectiva da ruína a partir do Museu das Missões, ao lado direito da foto está o antigo sino da igreja. Duas fotografias artísticas do lugar, que, assegurado como espaço de valor histórico e cultural, já possibilitava enquadramentos representativos desse discurso sensível e poético sobre o passado.

As fotos-postais com mais de seis décadas tornaram-se simbólicas, tendo seu enquadramento e imagens repetidos - salvo as poucas alterações na composição da paisagem - por inúmeras outras câmeras, e impressos em inúmeros outros postais turísticos e propagandas publicitárias. São exemplares da construção de um discurso patrimonial que tornam o sino, a árvore e a ruína em elementos pictóricos de uma obra, uma pintura que ultrapassa as bar-

Figuras 7 e 8. Fotografias/postais de São Miguel das Missões. Entre as décade 1940 e 1950
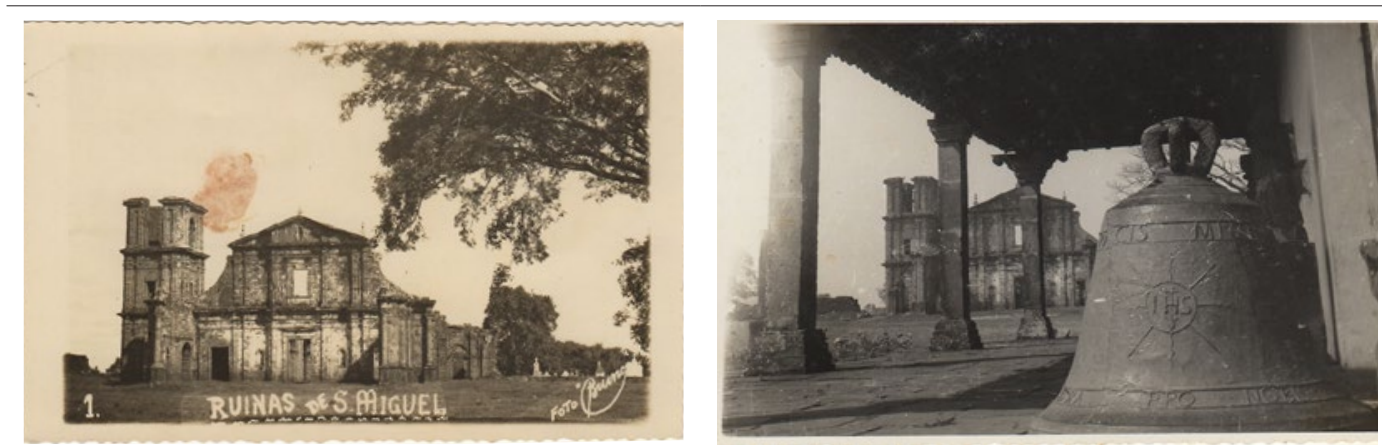

Fonte: Acervo da fototeca do AHMACPS. Santo Ângelo/RS. Coleção: Fotógrafo Bruno Schmidt. 
reiras da tela e se concretiza na paisagem real do lugar. O discurso romantizado da paisagem que atua sobre os sentimentos de identidade em relação ao lugar, ativados pelas relações e percepções sinestésicas dos corpos que se relacionam com o ambiente, são visíveis através das representações dos cartões postais, guias turísticos e outros materiais desse tipo (Tilley, 2006). Essas imagens afirmavam nesse período a supremacia dos bens de pedra e cal, da obra barroca e dos valores artísticos e estéticos em grande parte baseados nos valores europeus.

A intervenção humana na natureza foi transformando São Miguel, lembrando que a paisagem se constitui desse acúmulo de elementos que remetem ao passado. Para Milton Santos (1996) essa sobreposição de elementos materiais é que caracterizam relações que foram únicas em determinado tempo e lugar. A manutenção desses elementos representa a convivência de diferentes referências memoriais, carregados, no entando, ao mesmo tempo, de significados particulares e de referenciais identitários que se pretendem coletivos.

Reatualizada no imaginário local, a monumentalidade reforçada pelas políticas públicas, vai se transformando, através dos discursos empregados a elas, em uma espécie de mito fundador do sítio missioneiro e dos Sete Povos das Missões. Entre outros aportes, esse discurso aparece, por exemplo, nas músicas e poesias de artistas da região, como nesse trecho da "Payada das Missões" no álbum lançado por Jayme Caetano Braun em 1983:
E se fui índio primeiro/ Deste chão abarbarado/Antes de ser espoliado/ Pelo ibérico estrangeiro/Depois de ser missioneiro/ Não caí sem resistência/ E na bárbara pendência/Do taura - sem Deus, nem lei/ Eu mesmo me aquerenciei/Dentro da própria querência.

E se ela me foi tomada/ Num raio guacho de luz/ Quando a beleza da cruz/ Curvou-se à força da espada/ Extinta a chama sagrada/Que toda cultura encerra/ Eu que fui morto na guerra/ Num barbaresco repuxo/ Me transformei em gaúcho/E renasci sobre esta terra.

Figura 9. Cartão Postal. Brasil Turístico. Julho de 1966

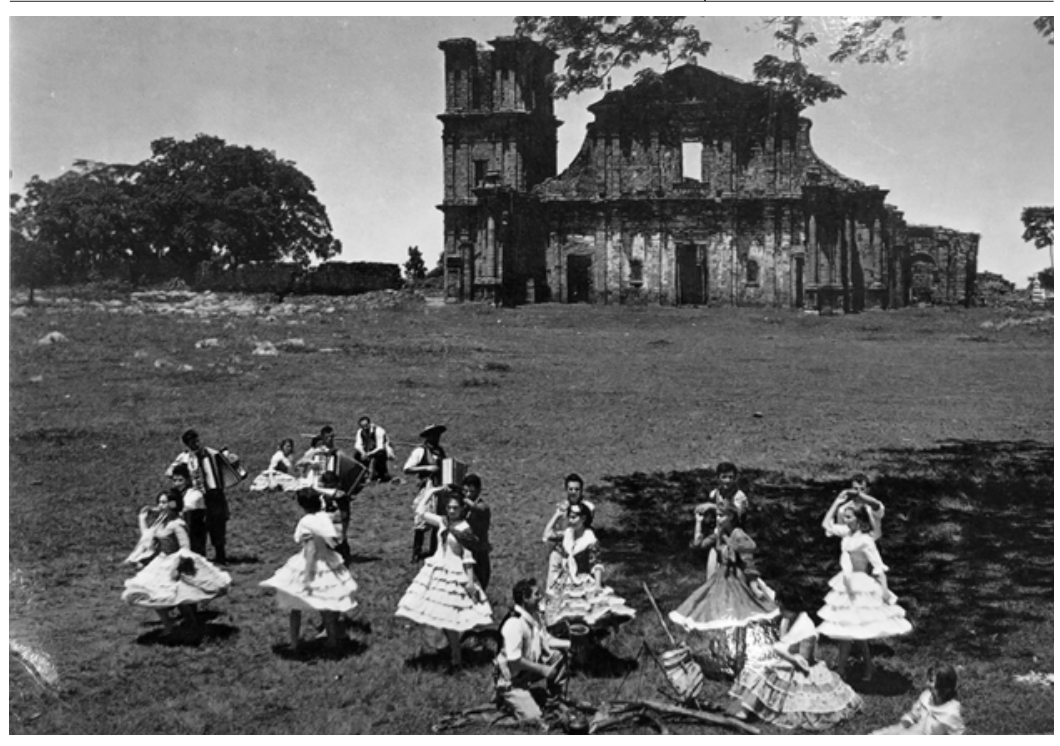

Fonte: Instituto de estudos Brasileiros - USP. Fundo Ernani Brum. ESB-RS-051.

As letras de músicas de cantores regionalistas, com grande apelo emocional são

territarias 33 
${ }^{13}$ Movimento Tradicionalista Gaúcho (MTG) iniciou sob a liderança de um grupo de jovens de Porto Alegre no ano de 1947. Estes jovens urbanos buscavam em costumes do gentílico do meio rurale, em fatos da história do Rio Grande do Sul, as referências para a afirmação de uma identidade do bomem gaúcho, num período marcado por transformações sociais e de migração para os grandes centros. $O$ movimento ganbou força nas décadas que se seguiram, e em 1966 foi instituida uma associação que representa e regulamenta as atividades dos Centros de Tradição Gaúcha (CTG) no Rio Grande do Sul e em outros estados do pais.

${ }^{14}$ Convenção para a salvaguarda do patrimônio cultural imaterial e Convenção sobre a proteção $e$ promoção da diversidade das expressões culturais.

territarias 33 exemplos da transposição da paisagem para o ambiente das artes e do folclore regional do Rio Grande do Sul. Da mesma forma, a imagem do cartão postal representado pela figura 9, traz em frente à ruína casais de peões e prendas, personagens típicos do gauchismo, em momento de dança com indumentária específica, aludindo à festa e aos costumes gastronômicos - vê-se na imagem também o churrasco preparado no fogo de chão -, numa demonstração da junção do lugar patrimonializado como referencial para um movimento, ${ }^{13}$ que no período da fotografia, se expandia como legitimador de uma identidade do povo do Rio Grande do Sul. Por outro lado, esse processo também contribuía para lançar outros significados ao lugar, numa espécie de reocupação e releitura do mesmo à sombra de novas perspectivas da compreensão dos quadros culturais e sociais da segunda metade do século XX.

Como é possível observar, esses novos usos do patrimônio foram trazendo para o debate as emergências no campo da cultura. Essas questões estiveram à luz da discussão no campo de atuação das agências públicas de preservação nas últimas décadas. Os temas do patrimônio imaterial e da diversidade cultural passaram a pautar de maneira proeminente as ações brasileiras no âmbito da cultura no princípio do século XXI. As Convenções da Unesco de 2003 e $2005^{14}$ afirmaram mundialmente esse novo modelo de atuação sobre o patrimônio, que já vinha se desenvolvendo na complexidade do cenário de um mundo em globalização.

A fotografia da imagem 10 representa essa transformação, os indígenas da Aldeia M’bya Guarani Tekoa Kóénju de São Mi-

Figura 10. "Crianças Guarani, brincando em frente a redução São Miguel Arcanjo"

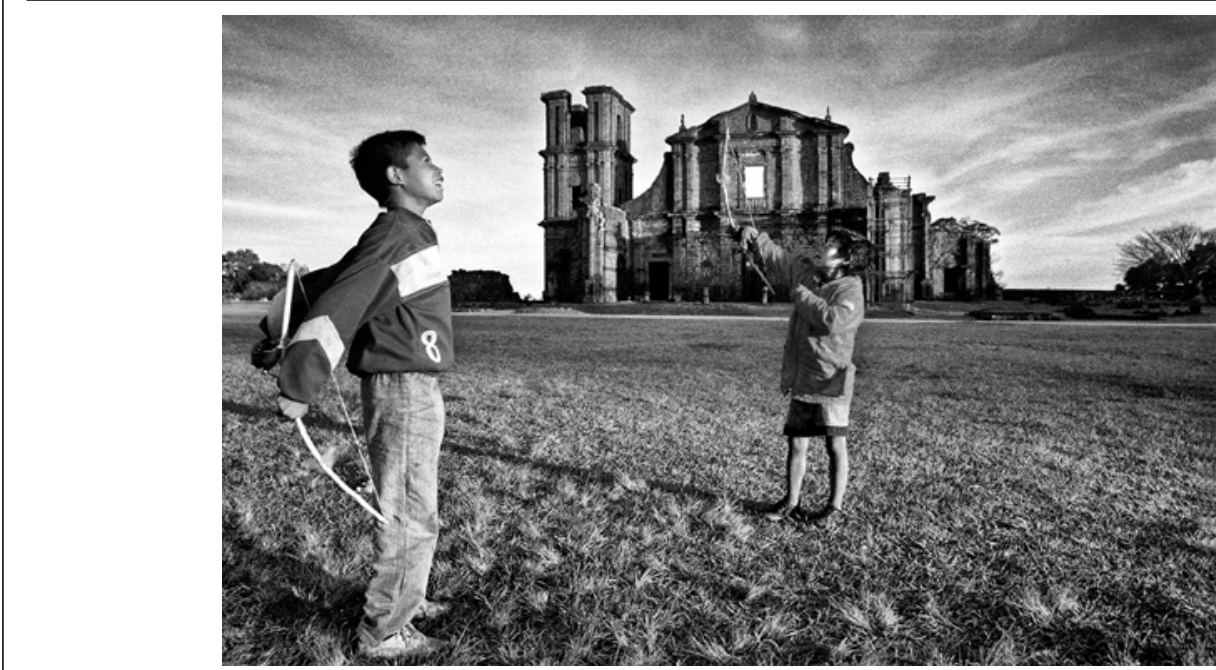

Fonte: Acervo particular do fotógrafo. Data: Março de 2000. Fotógrafo: Tadeu Vilani. 
guel das Missões passaram a atuar sobre o espaço do sítio com a venda do seu artesanato e tiveram suas imagens incluídas na paisagem do sítio. Isso também ocorreu a partir da atuação do Instituto do Patrimônio Histórico e Artístico Nacional (IPHAN) e da Unesco, ou seja, ações dessas agências dentro de um discurso contemporâneo de valorização dos entes humanos e culturas tradicionais que compõem os patrimônios. A imagem, originalmente em preto e branco, acentua os contornos das ruínas e das figuras humanas e contrasta a alegria de uma brincadeira dos meninos e a dramaticidade das ruínas junto ao céu de um fim de tarde. Na fotografia, assim como em outros materiais publicitários mais recentes sobre São Miguel, vemos as figuras dos indígenas frente ao monumento, refletindo na paisagem uma composição antropológica do espaço cultural e a valorização subjetividade na constituição do patrimônio.

\section{Conclusão}

As fotografias são uma das formas de compreender a história do patrimônio cultural brasileiro a partir de São Miguel das Missões. O patrimônio cultural de cidade, reconhecido pela Unesco em 1984 como patrimônio mundial, tem na imagem das ruínas da antiga igreja o ícone de mais força do contexto identitário da região das missões no Brasil. Uma construção inspirada em um templo europeu, junto às longínquas planícies do período colonial, a silhueta do bem arquitetônico foi exortada pela voz dos viajantes do século XIX, valo- rada por sua antiguidade e historicidade pelos imigrantes europeus do século xx e oficializada como monumento pela ação do poder público. Hoje estampa logotipos, programas turísticos, artesanatos, materiais de imprensa. Serve de cenário para o cinema e televisão. Uma imagem presente, e muitas vezes desconexa do seu significado primeiro, de igreja, de espaço de culto católico. Seu culto hoje é patrimonial, portador de mitos e significados, documento arquitetônico produtor de discursos que se transformaram e que seguem cambiantes.

São Miguel das Missões é hoje uma pequena cidade com uma população urbana significativa, que continua ressignificando a paisagem marcada pela trajetória patrimonial. A área tombada segue sendo o coração da cidade, protegida pela legislação do patrimônio. As ações interventivas do Estado mantiveram e constituíram uma paisagem política e poética que atua sobre a identidade local. Porém, assim como outros lugares com bens patrimoniais, São Miguel segue (re)construindo simbologias, frente aos desafios contemporâneos dos conflitos tanto no âmbito concreto das ações restritivas do Estado e da indústria do turismo, quanto da subjetividade das comunidades.

A transformação do lugar nos mais de três séculos desde a experiência missioneira dos jesuítas ocorreu de forma permenente. Muitos foram e são os atores dos processos de alteração do lugar: os jesuítas e os indígenas que construiram o povoado e a igre$\mathrm{ja}$, as autoridades das coroas ibéricas que faziam apenas cumprir os tratados de fronteira, os administradores posteriores que territarias 33

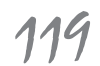


(des)organizaram o lugar (Santos, 2009), os indígenas que seguiram circulando pela região, as famílias que recolonizaram o lugar nos séculos XIX e XX, a população que começou o núcleo urbano que hoje está na volta da cidade, os guarani que hoje ocupam livremente o sítio histórico. São inúmeros sujeitos que ressignificam esse lugar com suas histórias e seus olhares, assim a paisagem se constituiu na imagem estática do postal e das fotos pessoais, mas também pelos significados culturais que lhe foi sendo atribuída. Esses significados, certamente distintos dependendo do olhar de cada indivíduo, que é resultado de um tempo e de uma cultura, só são possíveis também porque o lugar foi patrimonializado e organizado dessa forma. A ruína da igreja, o museu, o sino, as árvores, a grama, as estátuas, os guarani e seu artesanato, compõem o teatro vivo desse espetáculo patrimonial que compõe a paisagem física e a paisagem psiquica que se retroalimentam na configuração de identidades que tem como marco central a história colonial missioneira.

\section{Referências}

Baptista, J. (2008). Os marangatu e as divindades missionais: um problema de classificação do acervo do Museu das Missões. Anais do Musen Histivindades missionais: Janeiro, 40, 457-475.

Baptista, J. (2009). O Temporal: sociedades e espamissionais: J. São Miguel das Mis-

\section{territarias 33} 120 sões: Museu das Missões-IBRAM, (Dossiê Missões, I).
Brasil, Casa Civil. Presidência da República. Lei N. ${ }^{\circ} 601$ de 18 de setembro de 1850. Disponível em http://www.planalto.gov.br/ccivil_03/Leis/L06011850.htm

Brasil, Ministério da Cultura. Instituto de Patrimônio Histórico e Artístico Nacional (1994) 12. ${ }^{a}$ Coordenação Regional do IPHAN. Remanescentes da Igreja de São Miguel Arcanjo: Levantamento Cadastral. Porto Alegre: Pallotti.

Brasil, Ministério da Cultura. Instituto de Patrimônio Histórico e Artístico Nacional (s/d). Missões Jesuítas Guaranis no Brasil, ruínas de São Miguel das Missões. Disponível em http://portal. iphan.gov.br/montarDetalheConteudo.do;jsessionid=F4794396D02B497 213F6111E706A15E2? id=17248\&si gla=Institucional\&retorno=detalheIn stitucional

Braun, J. C. (1983). Payador das Missões. Em Payador. LP Tropical Discos do Brasil. Disponível em http://musicatradicionalista.com.br/musica/16127/ letra-payada-das-missoes.html

Choay, F. (2006). A alegoria do patrimonal. São Paulo: Estação Liberdade-UNESP.

Coelho, L. C. (2012). A Paisagem na fotografia: uma possibilidade de interpretação. Em R. Verdum et al. (Orgs.), Paisagem: leituras, significados e transformade $i$ (pp.207-225). Porto Alegre: Editora da UFRGS.

Colvero, R. B. (2013). Patrimônio Histórico de épocas e identidades diferentes: São Borja, "Terra Missioneira" e "Cidade dos Presidentes". Em W. Ashfield, M. 
Ferreira, A. M. Gonzáles (Orgs.), PatrimMaria Sosa zucchi; ép e Uruguai: os processos de patrimonialização e suas experiências (pp. 118-132). Pelotas: Ed. da Uni-versidade Federal de Pelotas.

Custídio, L. A. B., \& Stello, V. (2007). Preservación de las misiones: trayectoria de Brasil. Apuntes Revista de Estudios sobre patrimonio cultural, 20(1), 142-153.

Custódio, L. A. B. (1994). São Miguel Arcanjo: Levantamento Cadastral. Porto Alegre: Ministério da Cultura/IPHAN.

Félix, L. O. (1987). Coronelismo, borgismo e cooptaCultura/IPHA. Porto Alegre: Mercado Aberto.

Gomes, P. C. da C. (2012). A longa constituição do olhar geográfico. Revista GeoUECE 1(1), 1-7. Disponível em http://seer.uece.br/geouece.

Lamego, A. (1940). Os Sete Povos da Missões. Revista do Serviço do Patrimônio Histórico e Artístico Nacional, 4. Disponível em http://www.iphan.gov.br/ baixaFcdAnexo.do? $\mathrm{id}=3180$

Meira, A. L. G. (2008). O patrim em: 19/09/2013.baixaFcdAnexo. do?id=3180o.do?id=3180" lialização e sua atribuim em: 19/09/2013.baixaFcdAnexo.do?id=3180. (Tese de Doutorado, PROPUR, UFRGS).

Meliá, B., Nagel, L. M. (1995). Guaranies y jesuitas em tempo de las Misiones: una bibliografia didáctica. Santo Ângelo/ RS: URI, Centro de Cultura Missioneira; Assunción, Cepag.

Palacios, S., \& Zoffoli, E. (1991). Gloria y tragédia de las Misiones guaranies: historia de las reducciones jesuiticas durante los siglos XVII y XVIII en el Río de La Plata. Bilbao: Ediciones Mensajero.

Pesavento, S. J. (2007). Missões, um espaço no tempo: paisagens da memória Em S. J. Pesavento, A. L. Goelzer (Orgs.), Fronteiras do mundo ibérico: patrimônio, território e memória das Missões (pp. 51.63). Porto Alegre: Editora da UFRGS. Prats, L. (1998). El Concepto de Patrimonio Cultural. Pol Concepto de Pat, 27, 63-76.

Riegl, A. (2005). El culto moderno a los monumentos 3. ${ }^{\text {. }}$ Ed. Trad. Ana Pérez López. Madrid: La balsa de la Medusa.

Saint-Hilaire, A. de (1779-1853) (2002). Viagem ao Rio Grande do Sul. Tradução de Adroaldo Mesquita da Costa. Brasília: Senado Federal, Conselho Editorial. (Coleção O Brasil visto por estrangeiros).

Santos, M. C. dos. (2009). O Começo da ruína: administradores e indígenas na segunda metade do século XVIII. Em J. Baptista, \& M. C. dos Santos As Ruia Cristina dos.dministradores e indigena (Parte I. pp. 23-111). São Miguel das Missões: Museu das Missões-Ibram, (Dossiê Missões, III).

Santos, M. (1996). A Natureza do Espaço. Técnica e Tempo. Razão e Emoção. São Paulo: Hucitec.

Sepp, S. J. A. (1980). Viagem às missões Jesuiticas e trabalhos apostólicos. Belo Horizonte: Ed. Itatiaia; São Paulo: Ed. da Universidade de São Paulo.

Stello, V. F. (2005). Sítio arqueológico de São Miguel Arcanjo: avaliação conceitual dasintervenções 1925-1927 e 1938-1940. territarias 33

121 
(Tese de maestría, Universidade Federal do Rio Grande do Sul, Escola de Engenharia, Porto Alegre).

Tilley, C. (2006). Identity, Place, Landscape and Heritage. Journal of Material Culture, 11(1/2), 7-32.

\section{Documentos públicos,} jornais e fotografias

Documentos da Seção Intendência, Secretaria de Obras. Caixa $n^{\circ}$ 20. Arquivo Histórico Municipal Augusto César Pereira dos Santos. Secretaria Municipal de Cultura. Prefeitura Municipal de Santo Ângelo-RS.

Fotografias da fototeca do Arquivo Histórico Municipal Augusto César Perei- ra dos Santos. Secretaria Municipal de Cultura. Prefeitura Municipal de Santo Ângelo-RS.

A SEMANA. Santo Ângelo, Brasil, Rio Grande do Sul. 24 de fevereiro de 1921. Anno II. Num. 82. p. 01. Hemeroteca do Arquivo Histórico Municipal Augusto César Pereira dos Santos.

Cartão Postal Instituto de estudos Brasileiros - Universidade de São Paulo. Fundo Ernani Brum. ESB-RS-051.

Fotografia do "Levantamento Fotográfico Ruínas de São Miguel RS, 07/74 Município de Santo Ângelo". Arquivo do IPHAN São Paulo.

Fotografia do acervo pessoal. Fotografo Tadeu Vilani. 